\title{
Molecular conductors as nanoparticles in the presence of long-chain alkyl imidazolium salts
} or amphiphilic molecules: synthesis and thermoanalytical studies

\section{Soukaina Foulal ${ }^{1}$, Souad El Hajjaji ${ }^{*}$, Laszlo Trif ${ }^{2}$, Abdelaziz Sabbar ${ }^{3}$, Imane Chtioui ${ }^{4,5}$,} Dominique de Caro ${ }^{4,5}$, Christophe Faulmann ${ }^{4,5}$, Pascale de Caro ${ }^{6,7}$

${ }^{1}$ Laboratoire S3ME, Faculté des Sciences, Université Med V, Av Ibn battouta, BP1014, Agdal, Rabat, Maroc.

${ }^{2}$ Functional Interfaces Research Group, Institute of Materials and Environmental Chemistry, Research Centre for Natural Sciences, Hungarian Academy of Sciences, 1117 Budapest, Magyar Tudósok körútja, 2. Hungary.

${ }^{3}$ Equipe Matériaux, nanomatériaux, Faculté des Sciences, Université Med V, Av Ibn battouta, BP1014, Agdal, Rabat, Maroc.

${ }^{4}$ CNRS, LCC (Laboratoire de Chimie de Coordination), 205 route de Narbonne, BP 44099, 31077 Toulouse Cedex 4, France.

${ }^{5}$ Université de Toulouse, UPS, INPT, 31077 Toulouse Cedex 4, France.

${ }^{6}$ Université de Toulouse, INPT-ENSIACET, LCA (Laboratoire de Chimie Agro-Industrielle), 4 allée Emile Monso, 31030 Toulouse, France.

${ }^{7}$ INRA, UMR 1010 CAI, 31030 Toulouse, France.

${ }^{*}$ Corresponding author. E-mail: selhajjaji@hotmail.com, Tel: +212661303102

\begin{abstract}
Nanoparticles of two molecule-based conductors namely, TTF.TCNQ and TTF[Ni(dmit $\left.)_{2}\right]_{2}$, have been prepared in organic solution in the presence of ionic or non-ionic species bearing a long-chain alkyl group, acting as growth controlling agents. The size, morphology and state of dispersion of the nanoparticles depended on the nature of the growth-controlling agent and the reaction temperature. In the presence of a long-chain-alkyl-based ionic liquid at -50 ${ }^{\circ} \mathrm{C}$, electron micrographs evidence that TTF.TCNQ nano-objects are frequently elongated, whereas $\mathrm{TTF}\left[\mathrm{Ni}(\mathrm{dmit})_{2}\right]_{2}$ nanoparticles are aggregated. In the presence of a neutral long-chain-alkyl-based imine at room temperature, nanoparticles are spherical (mean diameter less than $20 \mathrm{~nm}$ ) and well dispersed. Vibration spectra evidence that the amounts of charge transfer for TTF.TCNQ and TTF $\left[\mathrm{Ni}(\mathrm{dmit})_{2}\right]_{2}$ as nano-objects are very similar to those for the same phases as bulk materials. According to the thermoanalytical investigations, the prepared nanoparticles are stable thermally up to approximately $200{ }^{\circ} \mathrm{C}$, their decomposition is generally a multi-step process. Their heat treatment results in various sulfur containing volatiles $\left(\mathrm{CS}_{2}, \mathrm{SO}_{2}, \mathrm{H}_{2} \mathrm{~S}\right)$, moreover $\mathrm{HCN}$ is also detected in the case of nitrogen containing molecules (TCNQ).
\end{abstract}

Keywords: tetrathiafulvalene, metal dithiolene complexes, nanoparticles, ionic liquids, $N$-octylfurfuryl-imine, thermoanalytical measurements.

\section{Introduction}

Molecule-based conductors attracted a renewed interest since the 2000s, in particular as regards to their processing as thin films or nano-objects [1]. This represents an important asset for potential applications. TTF.TCNQ and TTF[Ni(dmit $\left.)_{2}\right]_{2}$ (Fig. 1) belong to the family of donor-acceptor molecule-based conductors [2]. They are among the most studied molecular metals because of (i) the relatively low cost of the starting compounds; (ii) an easy synthesis; (iii) their interesting physical properties. TTF.TCNQ is a typical one-dimensional compound in which a charge transfer does exist between the TTF molecule (electron donor) and the TCNQ molecule (electron acceptor). It exhibits a metallike conductivity down to about $55 \mathrm{~K}[2]$. TTF[Ni(dmit $\left.)_{2}\right]_{2}$ exhibits a metallic behaviour down to $3 \mathrm{~K}$ and was the first metallo-organic-based material undergoing a superconducting transition (at $1.6 \mathrm{~K}$ under application of a hydrostatic pressure of $7 \mathrm{kbar})[3]$. 


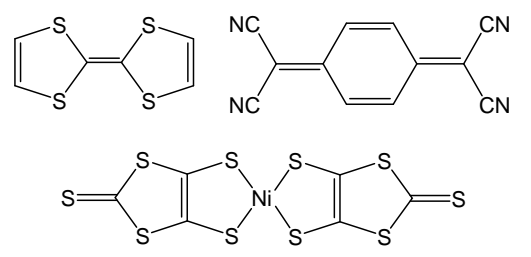

Fig. 1: Molecular formulas for TTF (left), TCNQ (right), and Ni(dmit) (bottom) $^{\text {(b) }}$

Nanowires of molecule-based conductors have been widely described [4-7]. This nanowire-like morphology is not surprising for quasi-1-D molecular conductors. However, these compounds do not show a natural tendency to grow as roughly spherical objects. Ionic liquids containing the $\mathrm{BMIM}^{+}$cation $\left(\mathrm{BMIM}^{+}\right.$: 1-butyl-3-methylimidazolium, Fig. 2) are very good candidates to stabilize spherical metallic nanoparticles [8]. In that case, reactions are conducted in pure ionic liquid, acting as both the solvent and stabilizing agent. We have recently reported the preparation of TTF.TCNQ and TTF $\left[\mathrm{Ni}(\mathrm{dmit})_{2}\right]_{2}$ nanoparticles in the presence of a mixture $[\mathrm{BMIM}][\mathrm{X}] /$ acetonitrile $\left(\mathrm{X}^{-}: \mathrm{BF}_{4}^{-}\right.$or $\left.\left(\mathrm{CF}_{3} \mathrm{SO}_{2}\right)_{2} \mathrm{~N}^{-}\right)$. Observed mean diameters were in the $20-40 \mathrm{~nm}$ range [9-12]. In our case, the growth as spherical nano-objects in an ionic liquid/acetonitrile mixture could be explained by a self-organization of imidazolium salts as nano-domains in the solvent, i.e., $\mathrm{CH}_{3} \mathrm{CN}$ [13]. Moreover, very small and well-dispersed metallic nanoparticles (diameter $<10 \mathrm{~nm}$ ) were extensively prepared by adding neutral amphiphilic molecules, such as long-alkyl chain amines or thiols, to the reaction medium [14]. The amphiphilic molecule, acting as a stabilizing agent, controlled the particle growth through coordination to the metal centre. We have recently shown that octylamine could also stabilize $40 \mathrm{~nm}$-TTF.TCNQ nanoparticles, in which TCNQ-OA (TCNQ whose a CN group has been substituted by an amino group) molecules were present at the particles surface and were responsible for their stabilization and their dispersibility in common organic solvents [15]. Furthermore, we have recently published the preparation of (TMTSF) ${ }_{2} \mathrm{ClO}_{4}$ nanocrystals (TMTSF: tetramethyltetraselenafulvalene) using the electrocrystallisation technique in the presence of $N$-octylfurfuryl-imine (Fig. 2), acting as a growth controlling agent [16]. Contrary to what observed in TTF.TCNQ/octylamine nanoparticles, the $N$ octylfurfuryl-imine molecule did not react with the TMTSF molecule but was presumably associated to the TMTSF through $\pi$-overlap via the furfuryl group during the growth whereas the $\mathrm{C}_{8}$ chain prevented nanocrystals from aggregation. High resolution transmission electron micrographs also evidenced that nanocrystals (sizes in the 20-70 nm range) were actually made of aggregated individual $2-6 \mathrm{~nm}$ nanoparticles [16].

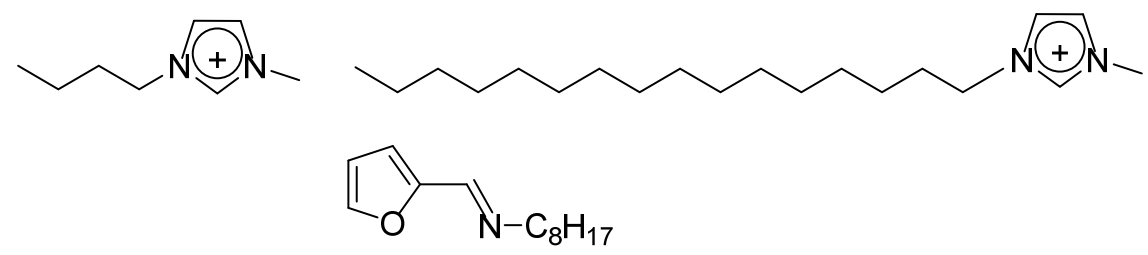

Fig. 2: Molecular formulas for $\mathrm{BMIM}^{+}$(left), $\mathrm{HDMIM}^{+}$(right), and N-octylfurfuryl-imine (bottom)

In order to obtain nanoparticles exhibiting mean diameters as small as $10 \mathrm{~nm}$, we have evaluated, in the present paper, the use of (i) a bulky imidazolium cation, i.e., 1-hexadecyl-3-methylimidazolium (HDMIM+, Fig. 2), (ii) the $N$ octylfurfuryl-imine amphiphilic molecule. The first part of this paper is devoted to the synthesis and spectral characterization of the molecule-based conducting nanoparticles, whereas the second part is dedicated to thermoanalytical studies of the TTF.TCNQ and TTF[Ni(dmit $\left.)_{2}\right]_{2}$ nanoparticles. 


\section{Materials and methods}

All syntheses have been carried out under an argon atmosphere using freshly distilled and degassed solvents. TTF was purchased from Sigma, TCNQ from Fluka, and [HDMIM] $\left[\left(\mathrm{CF}_{3} \mathrm{SO}_{2}\right)_{2} \mathrm{~N}\right]$ from Io-li-tec. Other starting compounds were prepared following previously described procedures: $(\mathrm{TTF})_{3}\left(\mathrm{BF}_{4}\right)_{2} \quad[17],\left[\left(n-\mathrm{C}_{4} \mathrm{H}_{9}\right)_{4} \mathrm{~N}\right]\left[\mathrm{Ni}(\mathrm{dmit})_{2}\right][18]$, and $N-$ octylfurfuryl-imine [19].

\subsection{TTF.TCNQ nanoparticles in the presence of [HDMIM] $\left.\left(\mathrm{CF}_{3} \mathrm{SO}_{2}\right)_{2} \mathrm{~N}\right]$}

A solution of $90 \mathrm{mg}$ of TTF $(0.44 \mathrm{mmol})$ and $780 \mathrm{mg}$ of $[\mathrm{HDMIM}]\left[\left(\mathrm{CF}_{3} \mathrm{SO}_{2}\right)_{2} \mathrm{~N}\right](1.32 \mathrm{mmol})$ in $20 \mathrm{~mL}$ of acetonitrile was added dropwise to a solution of $90 \mathrm{mg}$ of TCNQ $(0.44 \mathrm{mmol})$ in $20 \mathrm{~mL}$ of acetonitrile at $-50{ }^{\circ} \mathrm{C}$. A fine black precipitate was obtained as soon as the TTF/[HDMIM $]\left[\left(\mathrm{CF}_{3} \mathrm{SO}_{2}\right)_{2} \mathrm{~N}\right]$ solution was added under stirring. Stirring was maintained over a period of $2 \mathrm{~h}$ at $-50^{\circ} \mathrm{C}$. The suspension was then allowed to warm to room temperature. The black solid was filtered off, washed with $3 \times 10 \mathrm{~mL}$ of acetonitrile and finally dried under vacuum. The resulting black powder was air stable (yield: $94 \%$ ).

\subsection{TTF[Ni(dmit $\left.)_{2}\right]_{2}$ nanoparticles in the presence of $[\mathrm{HDMIM}]\left[\left(\mathrm{CF}_{3} \mathrm{SO}_{2}\right)_{2} \mathrm{~N}\right]$}

A solution of $115 \mathrm{mg}$ of $\left[\left(n-\mathrm{C}_{4} \mathrm{H}_{9}\right)_{4} \mathrm{~N}\right]\left[\mathrm{Ni}(\mathrm{dmit})_{2}\right](0.16 \mathrm{mmol})$ in $12 \mathrm{~mL}$ of acetone was added dropwise to a suspension of $60 \mathrm{mg}$ of $(\mathrm{TTF})_{3}\left(\mathrm{BF}_{4}\right)_{2}(0.08 \mathrm{mmol})$ and $146 \mathrm{mg}$ of [HDMIM] $\left.\left(\mathrm{CF}_{3} \mathrm{SO}_{2}\right)_{2} \mathrm{~N}\right](0.24 \mathrm{mmol})$ in $5 \mathrm{~mL}$ of acetonitrile at $-50{ }^{\circ} \mathrm{C}$. A fine black precipitate was observed and stirring was maintained over a period of $2 \mathrm{~h}$ at $-50{ }^{\circ} \mathrm{C}$. The suspension was then allowed to warm to room temperature. The black solid was filtered off, washed with $3 \times 5 \mathrm{~mL}$ of acetonitrile and finally dried under vacuum. The resulting black powder was air stable (yield: $60 \%$ ).

\subsection{TTF[Ni(dmit) $\left.{ }_{2}\right]_{2}$ nanoparticles in the presence of $N$-octylfurfuryl-imine (chemical procedure)}

A solution of $46 \mathrm{mg}$ of $\left[\left(n-\mathrm{C}_{4} \mathrm{H}_{9}\right)_{4} \mathrm{~N}\right]\left[\mathrm{Ni}(\mathrm{dmit})_{2}\right](0.066 \mathrm{mmol})$ in $10 \mathrm{~mL}$ of acetone was added dropwise to a solution of $26 \mathrm{mg}$ of $(\mathrm{TTF})_{3}\left(\mathrm{BF}_{4}\right)_{2}(0.033 \mathrm{mmol})$ and $23 \mu \mathrm{L}$ of $N$-octylfurfuryl-imine $(0.099 \mathrm{mmol})$ in $4 \mathrm{~mL}$ of acetonitrile at 25 ${ }^{\circ} \mathrm{C}$. A fine black precipitate was observed and stirring was maintained over a period of $6 \mathrm{~h}$ at $25^{\circ} \mathrm{C}$. The black solid was filtered off, washed with $3 \times 5 \mathrm{~mL}$ of acetonitrile and finally dried under vacuum. The resulting black powder was air stable (yield: $55 \%$ ).

\subsection{TTF[Ni(dmit) $]_{2}$ nanoparticles in the presence of $\mathrm{N}$-octylfurfuryl-imine (electrochemical procedure)}

The synthesis took place in a $\mathrm{H}$-shaped electrocristallization cell with a platinum wire in each compartment separated by a glass frit in the $\mathrm{H}$ cross piece. TTF $(10 \mathrm{mg} ; 0.05 \mathrm{mmol}),\left[\left(n-\mathrm{C}_{4} \mathrm{H}_{9}\right)_{4} \mathrm{~N}\right]\left[\mathrm{Ni}(\mathrm{dmit})_{2}\right](70 \mathrm{mg} ; 0.10 \mathrm{mmol})$, $34 \mu \mathrm{L}$ of $N$-octylfurfuryl-imine $(0.150 \mathrm{mmol})$ and $12 \mathrm{~mL}$ acetonitrile were introduced in the anodic compartment. [ $(n-$ $\left.\left.\mathrm{C}_{4} \mathrm{H}_{9}\right)_{4} \mathrm{~N}\right]\left[\mathrm{Ni}(\mathrm{dmit})_{2}\right](10 \mathrm{mg} ; 0.014 \mathrm{mmol})$ and $12 \mathrm{~mL}$ acetonitrile were introduced in the cathodic compartment. Nanoparticles synthesis was conducted under galvanostatic conditions $\left(100 \mu \mathrm{A} . \mathrm{cm}^{-2}\right)$ during 2 days at room temperature. During electrolysis, the content of the cell was vigorously agitated with a magnetic stirrer. The black powder was collected from the anode, washed with $2 \times 5 \mathrm{~mL}$ of acetonitrile and finally dried under vacuum. The resulting black powder was air stable (yield: $55 \%$ ).

\subsection{Characterization methods}

For transmission electron microscopy (TEM) observation, powder $(0.5 \mathrm{mg})$ was dispersed in diethyl ether $(2 \mathrm{~mL})$ under slow stirring for $1 \mathrm{~min}$. The TEM specimens were then prepared by evaporation of droplets of suspension 
deposited on carbon-supported copper grids. The experiments were performed on a JEOL Model JEM 1011 operating at $100 \mathrm{kV}$. Infrared spectra (in $\mathrm{KBr}$ matrix) were taken at room temperature on a Perkin Elmer Spectrum GX spectrophotometer. Raman spectra were recorded at $80 \mathrm{~K}$ using a DILOR XY micro-Raman (785 nm laser line). The room-temperature conductivity of the samples was measured on a compressed pellet by two-probe contacts using homemade equipment. The thermal analysis measurements were carried out on a SETARAM Labsys Evo TG-DSC thermal analyzer, in flowing high purity (6.0) Helium atmosphere (flow rate $90 \mathrm{~mL} \cdot \mathrm{min}^{-1}$ ), with a constant heating rate of $15 \mathrm{~K}^{\mathrm{min}}{ }^{-1}$, using standard $100 \mu \mathrm{L}$ alumina crucibles. The weighed sample amounts were in the range of 3-5 $\mathrm{mg}$ respectively. The measurements were carried out in the temperature range $30-1000{ }^{\circ} \mathrm{C}$, and the reference crucible was empty (no ref. material used). The samples were analyzed "as received". The results were processed using the thermoanalizer's Calisto Processing (v1.36) software. From every measurement, a previously recorded Baseline was subtracted. In some cases on the Heat Flow curves, a Savitzky \& Golay Smoothing filter (number of averaged points 75-100) was applied, in order to reduce the baseline noise. In the above-mentioned smoothing, the "Peak" filter was used in order to better preserve the shape of the signal peaks. Parallel with the TG-DSC measurement the analysis of the evolved gases/decomposition products were carried out on a Pfeiffer Vacuum OmniStar ${ }^{\mathrm{TM}}$ Gas Analysis System coupled to the above-described TGA. The gas splitters and transfer lines to the spectrometer were thermostated at 290 ${ }^{\circ} \mathrm{C}$. The measurements were carried out in SEM Bargraph Cycles acquisition mode, in which the total ion current (TIC), the analog bar graph spectra (for structure determination), and the separate ion current of each scanned individual mass (115 masses) was recorded. The scanned mass interval was 5-120 amu, with a scan speed of $50 \mathrm{~ms}^{-\mathrm{amu}^{-1}}$, and the spectrometer was operated in electron impact mode.

\section{Results and discussion}

\subsection{Nanoparticles grown in the presence of 1-hexadecyl-3-methylimidazolium bis(trifluoromethylsulfonyl)imide} or $\mathbf{N}$-octylfurfuryl-imine: synthesis and spectral characterizations

The dropwise addition of a solution of TTF in [HDMIM] $\left[\left(\mathrm{CF}_{3} \mathrm{SO}_{2}\right)_{2} \mathrm{~N}\right] /$ acetonitrile (1 to 3 molar eq. of $\mathrm{HDMIM}^{+}$/TTF) into an acetonitrile solution of TCNQ at room temperature led to a black precipitate of TTF.TCNQ. Transmission electron micrographs exclusively evidenced sticks (Fig. 3). Moreover, TTF[Ni(dmit) $]_{2}$ as sticks was obtained by the dropwise addition of an acetone solution of $\left[\left(n-\mathrm{C}_{4} \mathrm{H}_{9}\right)_{4} \mathrm{~N}\right]\left[\mathrm{Ni}(\mathrm{dmit})_{2}\right]$ on $(\mathrm{TTF})_{3}\left(\mathrm{BF}_{4}\right)_{2}$ dispersed in [HDMIM][( $\left.\left(\mathrm{CF}_{3} \mathrm{SO}_{2}\right)_{2} \mathrm{~N}\right] /$ acetonitrile (1 to 3 molar eq. of $\mathrm{HDMIM}^{+} / \mathrm{TTF}$, Fig. 3). Thus, at room temperature and for molar ratios explored, [HDMIM] $\left[\left(\mathrm{CF}_{3} \mathrm{SO}_{2}\right)_{2} \mathrm{~N}\right]$ did not play its role of growth controlling agent as it was the case for [BMIM] $\left[\mathrm{BF}_{4}\right]$ or $[\mathrm{BMIM}]\left[\left(\mathrm{CF}_{3} \mathrm{SO}_{2}\right)_{2} \mathrm{~N}\right]$ [9-11]. When the same reactions were carried out at $-50{ }^{\circ} \mathrm{C}$, TTF.TCNQ and $\mathrm{TTF}\left[\mathrm{Ni}(\mathrm{dmit})_{2}\right]_{2}$ were grown as nanoparticles (Fig. 3). For TTF.TCNQ, transmission electron micrographs showed a mixture of roughly spherical nanoparticles (diameters in the 15-40 nm range) and elongated nanoparticles (20-30 nm $\times$ 50-100 nm). For TTF $\left[\mathrm{Ni}(\mathrm{dmit})_{2}\right]_{2}$, nanoparticles exhibited diameters in the $10-30 \mathrm{~nm}$ range but were frequently agglomerated. At low temperatures, i.e. $-50{ }^{\circ} \mathrm{C}$, the bulky [HDMIM] $\left[\left(\mathrm{CF}_{3} \mathrm{SO}_{2}\right)_{2} \mathrm{~N}\right]$ species could control the growth of the two molecular conductors as nano-objects, but these results were not quite satisfactory in terms of size, morphology, and state of dispersion. Indeed, as specified in the introduction, better results were obtained in the presence of the butylsubstituted imidazolium salt, i.e., [BMIM] $\left[\left(\mathrm{CF}_{3} \mathrm{SO}_{2}\right)_{2} \mathrm{~N}\right][10,11]$.

Metal dithiolene complexes have recently been evaluated as active components for the fabrication of organic thermoelectric generators [20]. Performances of these generators were expected to be enhanced with the active matter at the nano-scale and finely dispersed. It is the reason why we have evaluated the use of $N$-octylfurfuryl-imine for the growth of TTF[Ni(dmit $\left.)_{2}\right]_{2}$ small particles either by a chemical or an electrochemical route. The chemical route was 
similar to that described above, using $(\mathrm{TTF})_{3}\left(\mathrm{BF}_{4}\right)_{2}$ and $\left[\left(n-\mathrm{C}_{4} \mathrm{H}_{9}\right)_{4} \mathrm{~N}\right]\left[\mathrm{Ni}(\mathrm{dmit})_{2}\right]$ and simply replacing [HDMIM] $\left[\left(\mathrm{CF}_{3} \mathrm{SO}_{2}\right)_{2} \mathrm{~N}\right.$ ] by $N$-octylfurfuryl-imine (1 to 3 molar eq. of $N$-octylfurfuryl-imine/TTF). Transmission electron micrographs of the $\mathrm{TTF}\left[\mathrm{Ni}(\mathrm{dmit})_{2}\right]_{2}$ powder thus obtained evidenced well dispersed nanoparticles with a mean diameter of about $20 \mathrm{~nm}$ (Fig. 4). These particles exhibited diameters similar to those obtained with [HDMIM] $\left[\left(\mathrm{CF}_{3} \mathrm{SO}_{2}\right)_{2} \mathrm{~N}\right]$ (see above). However, when using $\mathrm{N}$-octylfurfuryl-imine, no agglomerates of particles were observed. We have also performed the galvanostatic oxidation of TTF in the presence of $\left[\left(n-\mathrm{C}_{4} \mathrm{H}_{9}\right)_{4} \mathrm{~N}\right]\left[\mathrm{Ni}(\mathrm{dmit})_{2}\right]($ both reactant and supporting electrolyte) and $N$-octylfurfuryl-imine ( 3 molar eq. of $N$-octylfurfuryl-imine/TTF) under vigorous stirring. After a few hours, the platinum anode was covered by a black powder of $\mathrm{TTF}\left[\mathrm{Ni}(\mathrm{dmit})_{2}\right]_{2}$. The electrocrystallization was run over a period of two days to obtain a larger amount of product. Transmission electron micrographs showed very well dispersed nanoparticles exhibiting a mean diameter of about $12 \mathrm{~nm}$ (Fig. 4). This result was the most satisfactory in terms of morphology (spherical particles), state of dispersion (no agglomerates) and smallness of the particles (the smallest ever published for TTF[Ni(dmit) $]_{2}$ ). The neutral amphiphilic molecule, $N$ octylfurfuryl-imine, allowed the preparation of small and well dispersed spherical nanoparticles presumably due to an efficient $\pi$ stacking with five-membered rings of both TTF and $\mathrm{Ni}(\mathrm{dmit})_{2}$, the octyl chain attached to the nitrogen atom external to the cycle preventing the nanoparticles from agglomeration.

TTF.TCNQ and TTF[Ni(dmit $\left.)_{2}\right]_{2}$ nanoparticles have been characterized by vibrational spectroscopy, i.e., infrared and Raman. Whatever the growth controlling agent used and its molar amount, spectra did not evidence signals for [HDMIM] $\left[\left(\mathrm{CF}_{3} \mathrm{SO}_{2}\right)_{2} \mathrm{~N}\right]$ or $N$-octylfurfuryl-imine. Its presence in solution was essential to control the growth of the molecular material as nanoparticles but it was not adsorbed to the particles surface in the final material. Infrared and Raman spectra evidenced the presence of both the electron donor (TTF) and the electron acceptor (TCNQ or $\left.\mathrm{Ni}(\mathrm{dmit})_{2}\right]_{2}$ ) within the nanopowders. Vibration spectra for TTF.TCNQ nanoparticles were shown on Fig. 5. They were very similar to those previously described for TTF.TCNQ nanoparticles grown in the presence of [BMIM][BF 4 ] [9]. In particular, in the infrared spectrum, the nitrile stretching mode $\left(v_{\mathrm{CN}}\right)$ at $2204 \mathrm{~cm}^{-1}$ allowed us to determine the amount of charge transfer from the TTF donor molecule to the acceptor TCNQ molecule. Using the linear correlation of $v_{\mathrm{CN}}$ for TCNQ as a function of the degree of charge transfer, we obtained a value of 0.56 , in relatively good agreement with that for single crystals, i.e., 0.59 [21]. Moreover, in the Raman spectrum, the $\mathrm{C}=\mathrm{C}$ stretching mode in TCNQ located at 1418 $\mathrm{cm}^{-1}\left(v_{4} \mathrm{a}_{\mathrm{g}}\right)$ gave a charge transfer of 0.55 [22]. Thus, according to infrared and Raman studies, the charge transfer in TTF.TCNQ as nanoparticles is rather similar to that on macroscopic single crystals. 


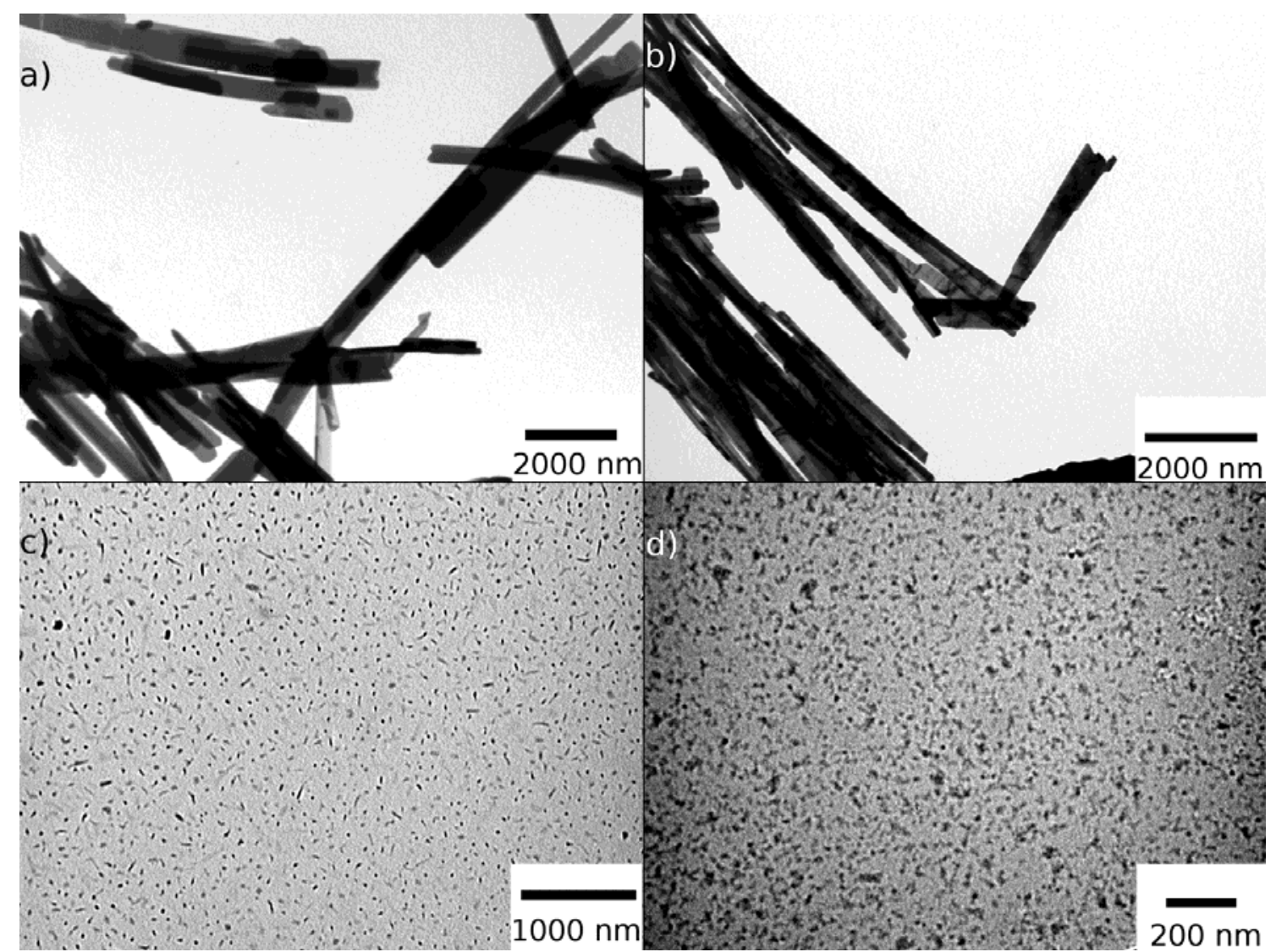

Fig. 3: Electron micrographs for molecule-based conductors grown in the presence of $[\mathrm{HDMIM}]\left[\left(\mathrm{CF}_{3} \mathrm{SO}_{2}\right)_{2} \mathrm{~N}\right](3$ molar eq.):

TTF·TCNQ (a: $\left.25^{\circ} \mathrm{C} ; \mathbf{c}:-50{ }^{\circ} \mathrm{C}\right)$ and TTF $\left[\mathrm{Ni}(\mathrm{dmit})_{2}\right]_{2}\left(\mathbf{b}: 25^{\circ} \mathrm{C} ; \mathbf{d}:-50{ }^{\circ} \mathrm{C}\right)$

Vibration spectra for TTF[Ni(dmit $\left.)_{2}\right]_{2}$ nanoparticles were shown on Fig. 5. They were similar to those described for $\mathrm{TTF}\left[\mathrm{Ni}(\mathrm{dmit})_{2}\right]_{2}$ nanoparticles elaborated in the presence of $[\mathrm{BMIM}]\left[\left(\mathrm{CF}_{3} \mathrm{SO}_{2}\right)_{2} \mathrm{~N}\right][11]$ or TTF$\left[\mathrm{Ni}(\mathrm{dmit})_{2}\right]_{2}$ nanowires electrodeposited on (001)-oriented silicon substrates [23, 24]. The infrared spectrum showed the $\mathrm{CH}$ ethylenic stretching vibration for TTF at $3087 \mathrm{~cm}^{-1}$ and the characteristic doublet present in all compounds containing the $\mathrm{M}(\mathrm{dmit})_{2}$ species (1071 and $\left.1053 \mathrm{~cm}^{-1}\right)$ [25]. The Raman spectrum evidenced modes related to the $\mathrm{Ni}(\mathrm{dmit})_{2}$ entity: 137, 343, 361, and $492 \mathrm{~cm}^{-1}$ [26]. Signals at 1430, 1471, and $1509 \mathrm{~cm}^{-1}$ were related to the TTF entity [27]. The more intense signal located at $1430 \mathrm{~cm}^{-1}$ was very sensitive to the amount of charge transfer between the electron donor TTF and the electron acceptor $\mathrm{Ni}(\mathrm{dmit})_{2}$. From this Raman peak, the degree of charge transfer was evaluated to 0.86 [28], in relatively good agreement with that obtained from band structure calculations, i.e., 0.80 [3].

Room-temperature conductivity measurements on TTF.TCNQ and TTF[Ni(dmit $\left.)_{2}\right]_{2}$ nanoparticle powders gave values in the $0.1-1 \mathrm{~S} \mathrm{~cm}^{-1}$ range. They were of the same order of magnitude than those reported for TTF.TCNQ and $\mathrm{TTF}\left[\mathrm{Ni}(\mathrm{dmit})_{2}\right]_{2}$ nanoparticle powders prepared in the presence of $[\mathrm{BMIM}]\left[\mathrm{BF}_{4}\right]$ or $[\mathrm{BMIM}]\left[\left(\mathrm{CF}_{3} \mathrm{SO}_{2}\right)_{2} \mathrm{~N}\right][9-11]$. They were obviously lower than those on single crystals [23] due to resistive boundaries between the particles. 

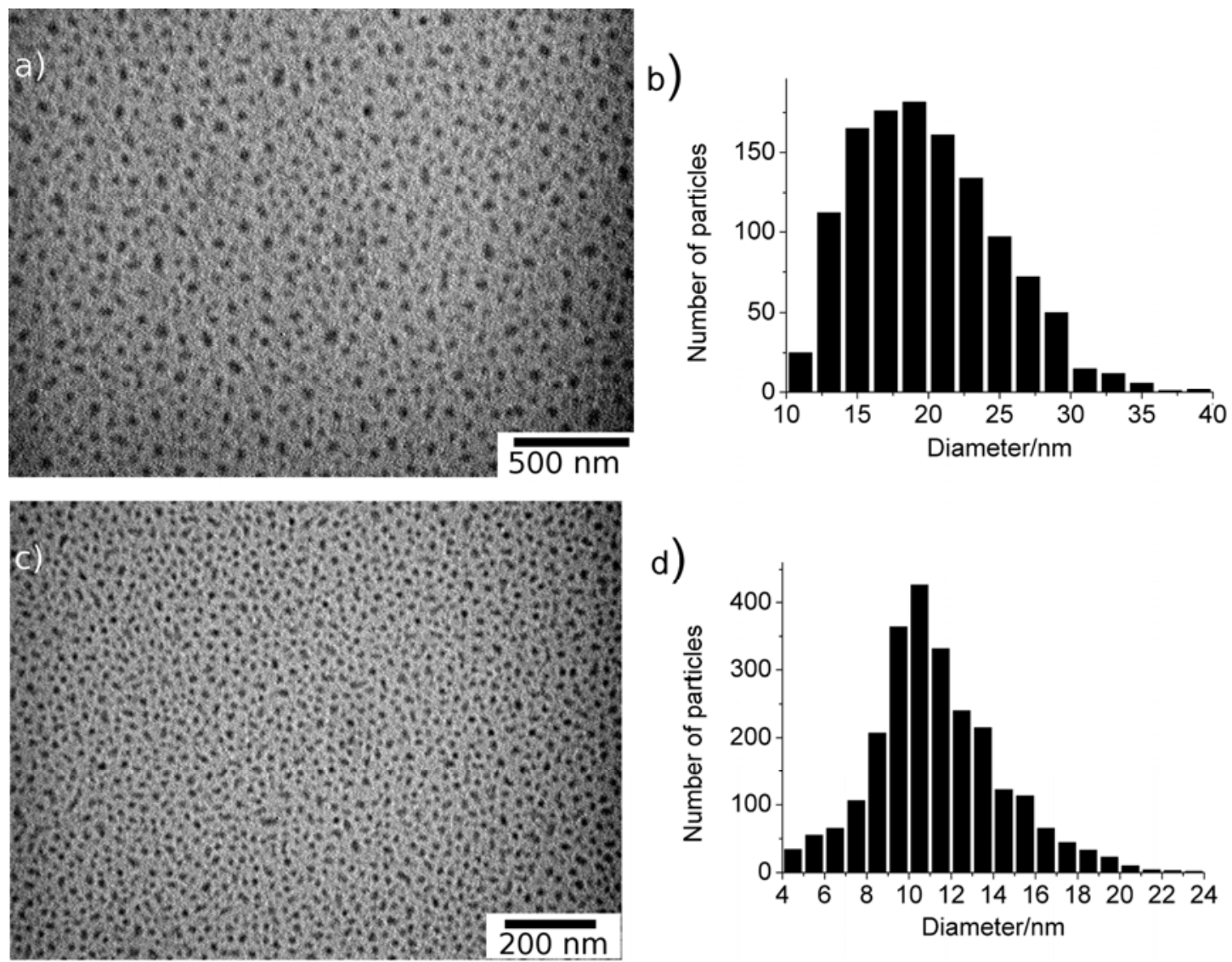

Fig. 4: Electron micrographs and size histograms for $\operatorname{TTF}\left[\mathrm{Ni}(\mathrm{dmit})_{2}\right]_{2}$ grown in the presence of $N$-octylfurfuryl-imine (3 molar eq.): chemical route $(\mathbf{a}-\mathbf{b})$; electrochemical route $(\mathbf{c}-\mathbf{d})$ 

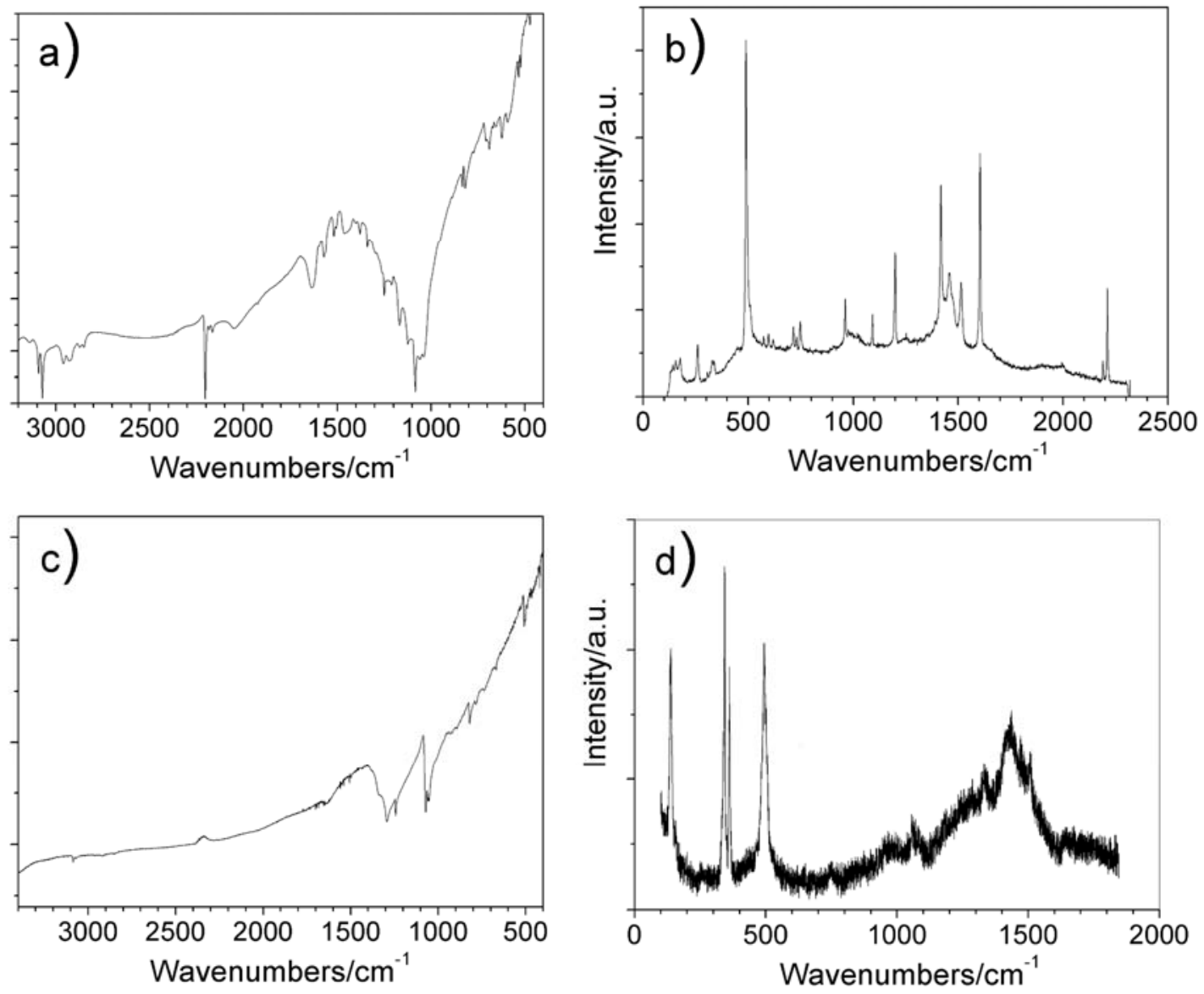

Fig. 5: Infrared and Raman spectra for TTF.TCNQ (a-b) and for TTF[Ni(dmit $\left.)_{2}\right]_{2}$ nanoparticles (c-d)

3.2. Nanoparticles grown in the presence of 1-hexadecyl-3-methylimidazolium bis(trifluoromethylsulfonyl)imide or $N$ octylfurfuryl-imine: thermoanalytical studies 


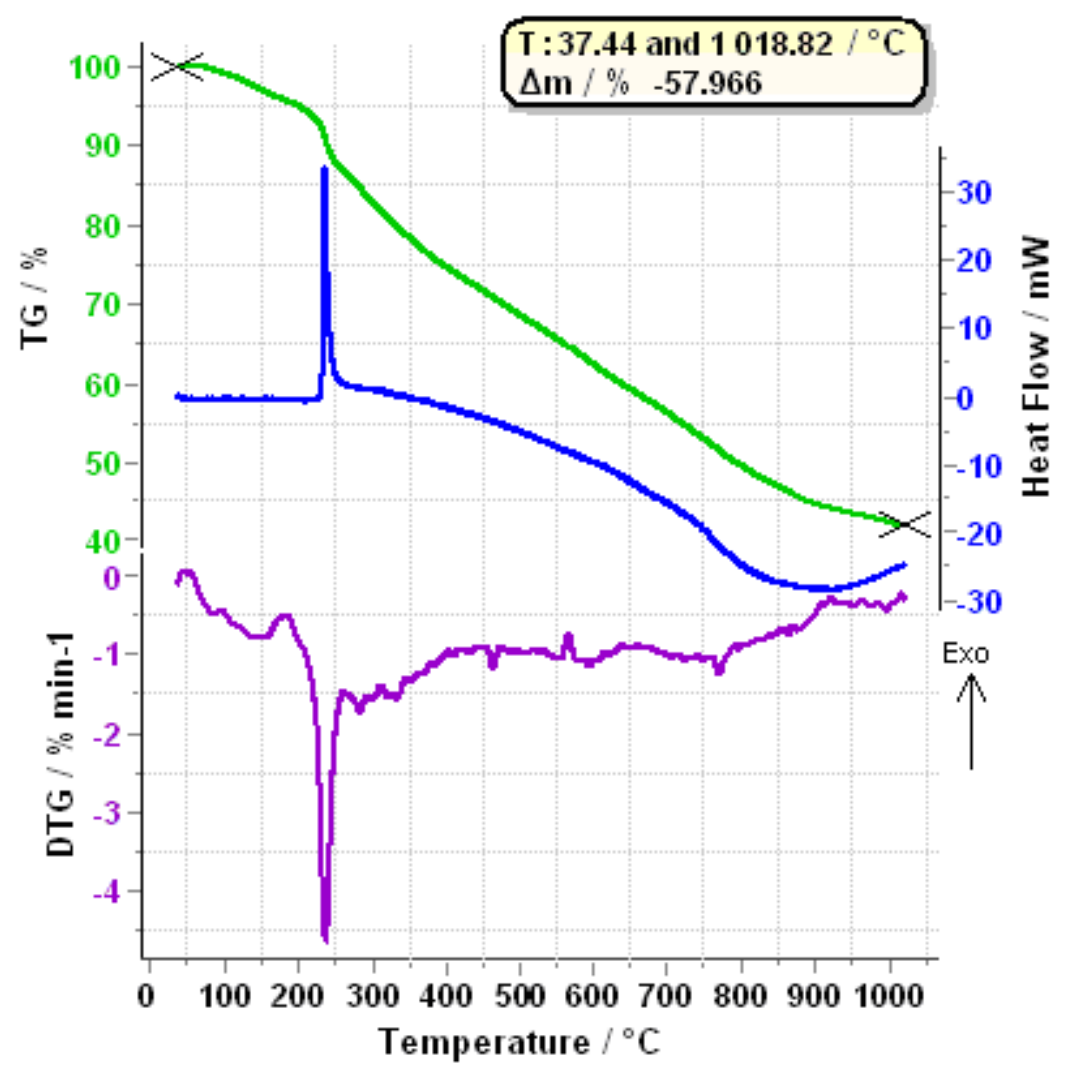

Fig. 6: TG-DTG-DSC trace of TTF-TCNQ molecule-based conductors grown in the presence of [HDMIM] $\left[\left(\mathrm{CF}_{3} \mathrm{SO}_{2}\right)_{2} \mathrm{~N}\right]\left(3\right.$ molar eq.) at $25^{\circ} \mathrm{C}$

Besides its wide application area, thermal analysis is an indispensable tool for the evaluation of thermal stability, degradation of organic molecular materials too. Muraoka et al. [29] have investigated the temperature dependence of the ac heat capacity of a molecule-based superconductor $\kappa$-(BEDT-TTF $)_{2} \mathrm{Cu}(\mathrm{NCS})_{2}$ under external pressures and with magnetic fields, while Ishikawa et al. [30] performed thermodynamic investigations by relaxation calorimetric technique on the organic superconductor $\kappa-(\text { BEDT-TTF })_{2} \mathrm{Ag}(\mathrm{CN})_{2} \mathrm{H}_{2} \mathrm{O}$. Bhattacharjee et al. [31] have used thermogravimetric analysis to study the thermal degradation of a bimetallic oxalate ligand based molecular magnetic material $\left\{\mathrm{N}\left(n-\mathrm{C}_{4} \mathrm{H}_{9}\right)_{4}\left[\mathrm{Fe}^{\mathrm{II}} \mathrm{Fe}^{\mathrm{III}}\left(\mathrm{C}_{2} \mathrm{O}_{4}\right)_{3}\right]\right\}_{\infty}$. They have found that the decomposition takes place in multiple steps, the chemical products and reaction pathways were established using TG measurement and supplemented by the IR and powder XRD studies. In our study we have also used simultaneous thermogravimetry-differential scanning calorimetry (TG-DSC) and mass spectrometric evolved gas analysis (MS-EGA) for the determination of decomposition intervals, steps and volatile degradation products on TTF.TCNQ and TTF[Ni(dmit $\left.)_{2}\right]_{2}$ molecule-based conductors. In view of the forthcoming integration of these nanomaterials in future thermoelectric generators, it is of key interest to study their thermoanalytical properties. This has been performed for both TTF.TCNQ and TTF[Ni(dmit $\left.)_{2}\right]_{2}$ nanoparticles, these latter being the most promising for thermoelectric applications as mentioned above.

On Fig. 6, the results of thermoanalytical investigations for TTF-TCNQ sticks grown at $25{ }^{\circ} \mathrm{C}$ are depicted. The green curve is the mass variation (TG), the blue curve is the Heat flow, while the violet curve corresponds to the derivative thermogravimetric curve (DTG). On the TG and DTG curves there can be seen, that the sample decomposes in 5 more or less differentiable steps (the limits of these steps are not shown in the Fig. 6). The first step is between 64.3 and $184.9^{\circ} \mathrm{C}$, with a mass loss of $4.4 \%$. This is due to the evaporation of the physically adsorbed water (obtained from the mass spectrometric evolved gas analysis measurements). The next mass loss step of $9.9 \%$ is more evident, and can 
be found in the temperature region of 187.3 and $274{ }^{\circ} \mathrm{C}$, this appears as a sharp peak on the DTG curve. This is also accompanied by a sharp exothermic peak on the Heat Flow curve (onset point $232.9{ }^{\circ} \mathrm{C}$, peak maxima $235.8^{\circ} \mathrm{C}$ and heat of decomposition $160 \mathrm{~J} . \mathrm{g}^{-1}$ ), which is due to a fast degradation reaction. Between 273.9 and $437.6{ }^{\circ} \mathrm{C}$ an additional amount of $13.2 \%$, while in the 440.5 and $709.4{ }^{\circ} \mathrm{C}$ region $16.7 \%$ is lost. In the last step the speed of the mass loss (on the DTG curve) decreases, between 712.5 and $1,013.7^{\circ} \mathrm{C} 13.2 \%$ of the starting material is lost. The total mass decrease in the investigated temperature region is $57.97 \%$.

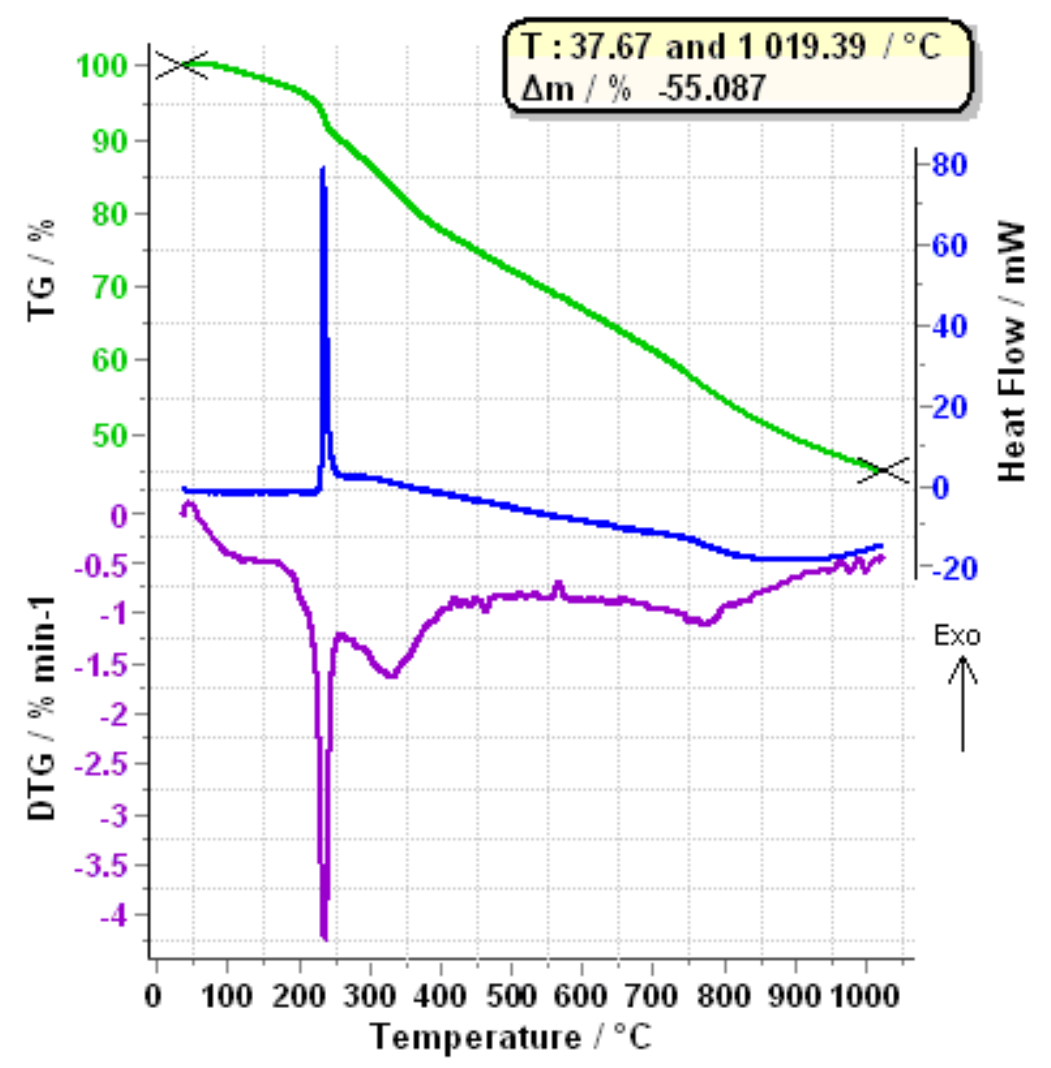

Fig. 7: TG-DTG-DSC trace of TTF-TCNQ molecule-based conductors grown in the presence of $[\mathrm{HDMIM}]\left[\left(\mathrm{CF}_{3} \mathrm{SO}_{2}\right)_{2} \mathrm{~N}\right](3$ molar eq. $)$ at $-50{ }^{\circ} \mathrm{C}$

On Fig. 7, the results of thermoanalytical investigations for TTF.TCNQ nanoparticles grown at $-50{ }^{\circ} \mathrm{C}$ are presented. By comparing the shape and run of all three curves with the ones presented on Fig. 6, it can be seen, that they are very similar. Even the mass loss intervals determined in the previous measurement are in good accordance. The temperature intervals, and the corresponding mass losses are the following: step $1-74.7$ and $184.7{ }^{\circ} \mathrm{C}$, mass loss $3 \%$, step $2-189.2$ and $260.2{ }^{\circ} \mathrm{C}$, mass loss $7.16 \%$, step $3-262.6$ and $432{ }^{\circ} \mathrm{C}$, mass loss $13.7 \%$, step $4-435.7$ and $684.4{ }^{\circ} \mathrm{C}$, mass loss $13.6 \%$ and step $5-687.2$ and $1,017.4{ }^{\circ} \mathrm{C}$, mass loss $16.9 \%$. In this case the total mass loss is $55.1 \%$. The parameters of the exothermic peak, which accompanies the mass loss in the second step, are the following: onset point $233.4{ }^{\circ} \mathrm{C}$, peak maxima $234.2{ }^{\circ} \mathrm{C}$ and heat of decomposition $166.2 \mathrm{J.g}^{-1}$. Due to the similarity of the two set of results (Fig. 6 and Fig. 7), we can draw the conclusion, that the preparation method, and the size and shape of the obtained particles (i.e. sticks and nanopowder) do not influence the thermal behavior of both materials. Moreover, the investigated materials are thermally stable up to $180-190{ }^{\circ} \mathrm{C}$, which is in good agreement with the results of de Caro et al. [15].

Parallel with the thermoanalytical measurement, the analysis of the evolved gases/decomposition products was carried out. On Fig. 8, the ion currents (i.e. concentration variation) of some selected fragments/molecules are plotted 
against temperature. Between 200 and $250{ }^{\circ} \mathrm{C}$, a sharp rise in the intensity of all curves can be observed. This corresponds to the second mass loss step in Fig. 7. By plotting the analog spectra of the evolved volatiles at $236{ }^{\circ} \mathrm{C}$ (Fig. 9), where the speed of mass loss is the highest (this corresponds to the minima of the DTG curve), the formula of various fragments/molecules can be deduced, thus the products of the thermal degradation can be identified. On Fig. 9, $\mathrm{m} / \mathrm{z}-78 \mathrm{amu}$ corresponds to the $\mathrm{C}_{6} \mathrm{H}_{6}$ formula, which is one of the degradation products of TCNQ, while to the $\mathrm{m} / \mathrm{z}-$ $76 \mathrm{amu}$ corresponds to the $\mathrm{C}_{6} \mathrm{H}_{4}$ and/or $\mathrm{CS}_{2}$ formulae, the former resulting from TCNQ and the latter from the breakage of the TTF. Another very characteristic decomposition products can also be observed, as the CS (m/z -44 amu, daughter ion of $\left.\mathrm{CS}_{2}\right), \mathrm{CH}_{2} \mathrm{CN}(\mathrm{m} / \mathrm{z}-40 \mathrm{amu}), \mathrm{HCN}$ and $\mathrm{CN}(\mathrm{m} / \mathrm{z}-27 \mathrm{amu}$ and $\mathrm{m} / \mathrm{z}-26$ amu respectively).

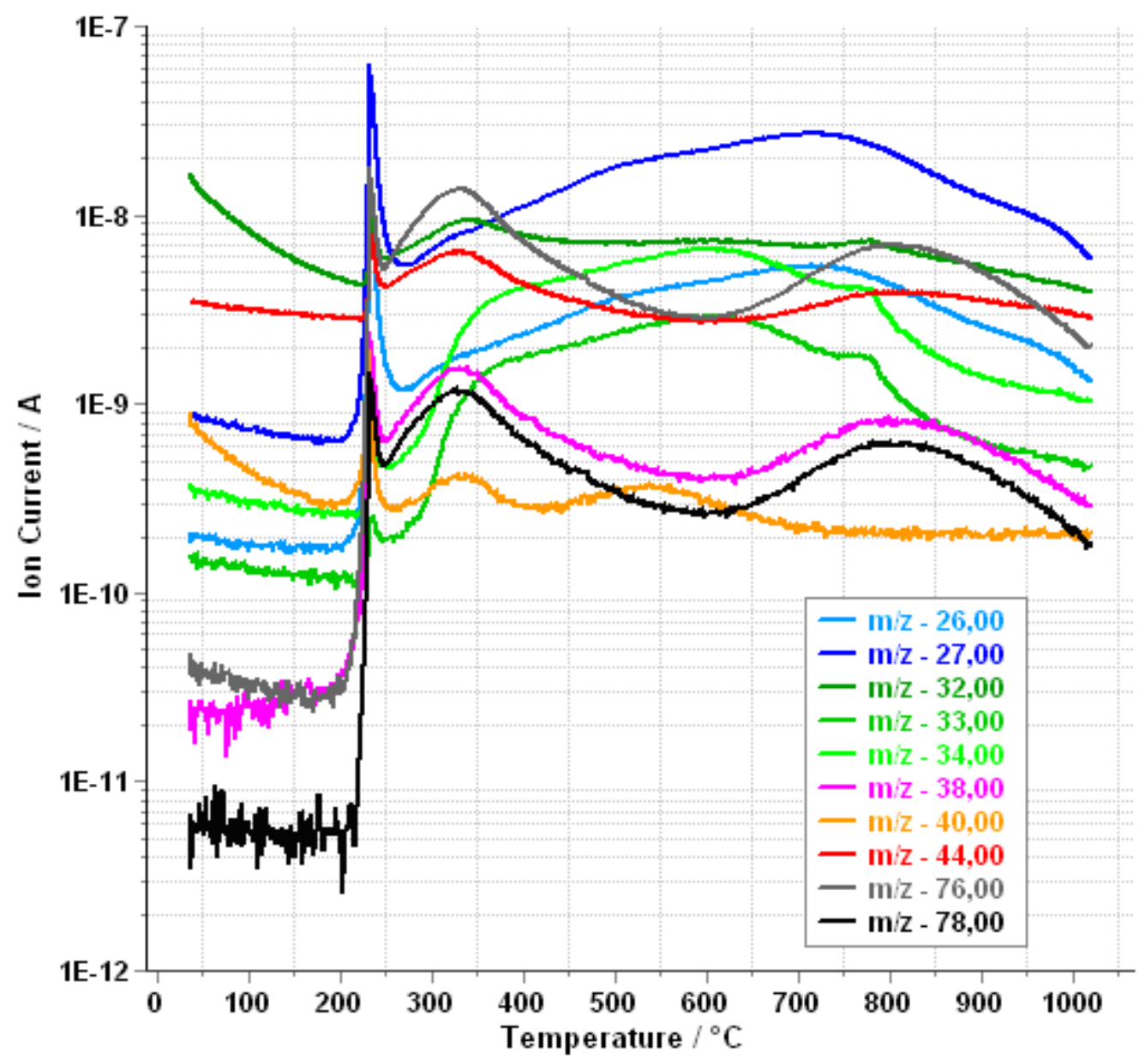

Fig. 8: Ion currents (concentration variation) of some selected fragments plotted against temperature

By following the course of the various fragments identified, a rough degradation mechanism can be proposed. In the 200 and $250{ }^{\circ} \mathrm{C}$ interval (Fig. 8), the intensity of all fragments/molecules is rising, which means, that the TTF·TCNQ structure collapsed and in some manner degraded thermally, from now on a continuous degradation occurs, with release of various characteristic degradation products. During the third mass loss step (between 262.6 and $432{ }^{\circ} \mathrm{C}$ ), the degradation products of both TTF and TCNQ appear, while in the last mass loss step the volatiles resulting from TCNQ are dominating $(\mathrm{m} / \mathrm{z}-78$ amu and $\mathrm{m} / \mathrm{z}-76 \mathrm{amu})$. 


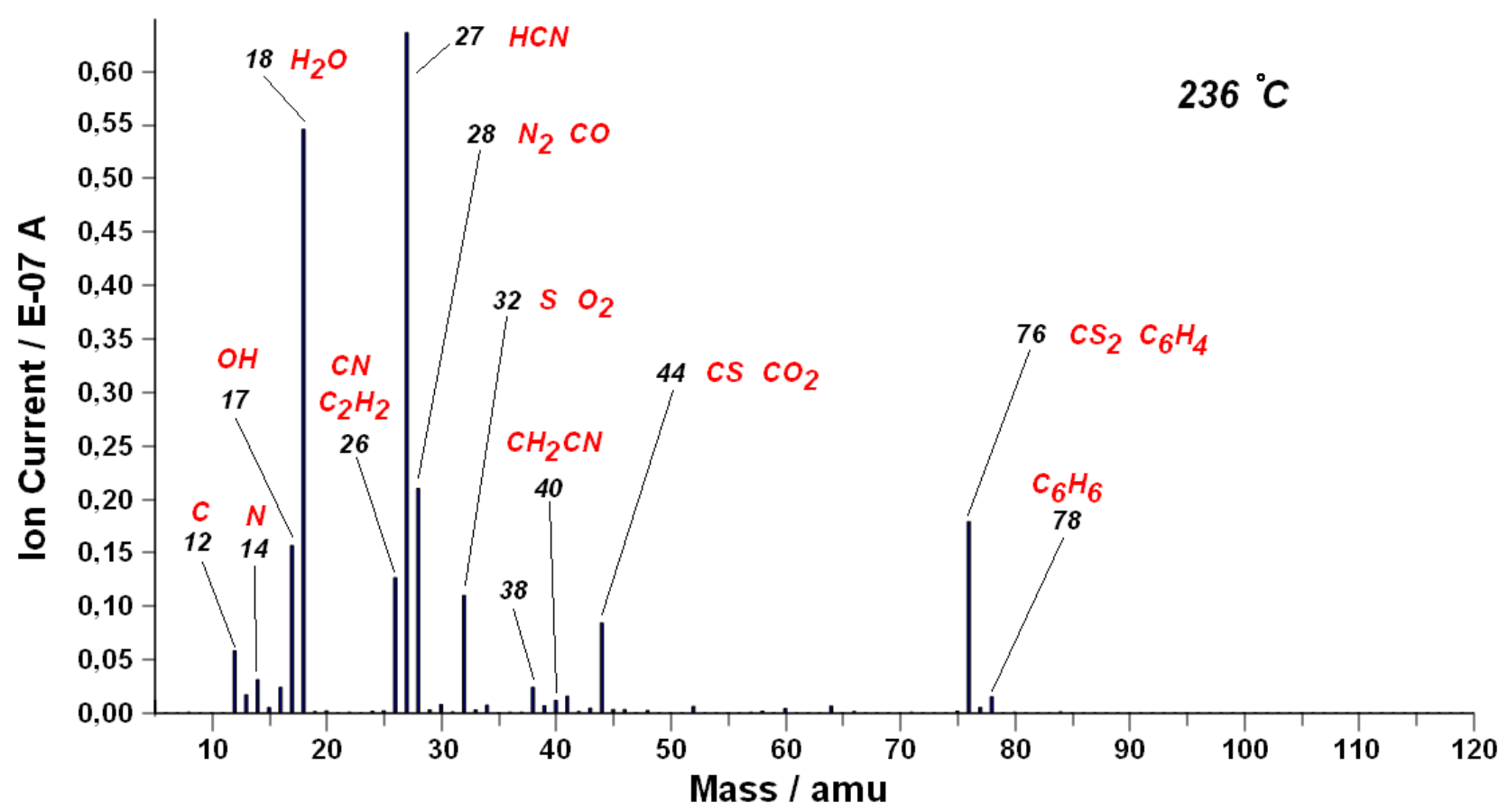

Fig. 9: Analog mass spectra of the evolved volatiles (at $236^{\circ} \mathrm{C}$ ) of TTF·TCNQ molecule-based conductors grown in the presence of [HDMIM] $\left[\left(\mathrm{CF}_{3} \mathrm{SO}_{2}\right)_{2} \mathrm{~N}\right]$

(3 molar eq.) at $-50{ }^{\circ} \mathrm{C}$

The evolution maxima of $\mathrm{HCN}$ and $\mathrm{CN}(\mathrm{m} / \mathrm{z}-27 \mathrm{amu}$ and $\mathrm{m} / \mathrm{z}-26 \mathrm{amu})$, resulting from TCNQ is roughly around $710{ }^{\circ} \mathrm{C}$. The presence of degradation products (e.g. fluorinated compounds), which could result from $[\mathrm{HDMIM}]\left[\left(\mathrm{CF}_{3} \mathrm{SO}_{2}\right)_{2} \mathrm{~N}\right]$ were not identified, which agrees with the results obtained from the vibrational spectroscopy measurements. 


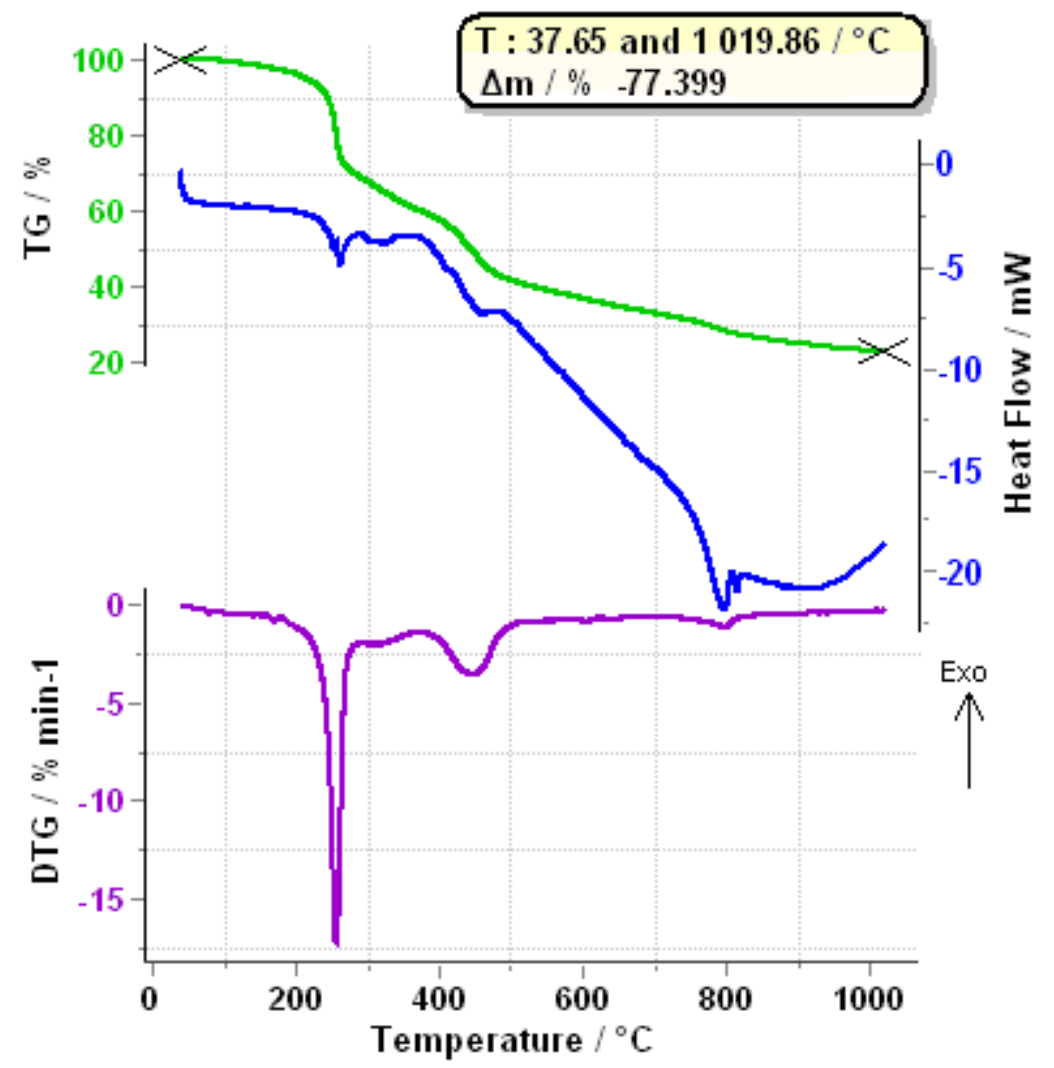

Fig. 10: TG-DTG-DSC trace of $\mathrm{TTF}\left[\mathrm{Ni}(\mathrm{dmit})_{2}\right]_{2}$ molecule-based conductors grown in the presence of [HDMIM] $\left[\left(\mathrm{CF}_{3} \mathrm{SO}_{2}\right)_{2} \mathrm{~N}\right](3$ molar eq. $)$ at $25^{\circ} \mathrm{C}$

On Fig. 10, the TG-DTG-DSC trace of TTF[Ni(dmit $\left.)_{2}\right]_{2}$ sticks grown at $25{ }^{\circ} \mathrm{C}$ are shown, while on Fig. 11 for those particles, which were grown at $-50{ }^{\circ} \mathrm{C}$. Again, both materials behave in the same way from thermal point of view. In both cases, based on TG and DTG curves, five mass loss steps can be differentiated, from which the second and third step is well defined. The second, third and the last step is accompanied by a small, broad endotherm. The corresponding mass losses for each step are listed below: on Fig. 10, step $1-74.2$ and $194.1{ }^{\circ} \mathrm{C}$, mass loss $2.7 \%$, step $2-198.9$ and $330.7{ }^{\circ} \mathrm{C}$, mass loss $30.3 \%$, step $3-331.9$ and $528.9^{\circ} \mathrm{C}$, mass loss $23.9 \%$, step $4-530.5$ and $735.1{ }^{\circ} \mathrm{C}$, mass loss $9.1 \%$ and step $5-738$ and $1,014.2^{\circ} \mathrm{C}$, mass loss $8.4 \%$. The total mass loss is $74.9 \%$. 


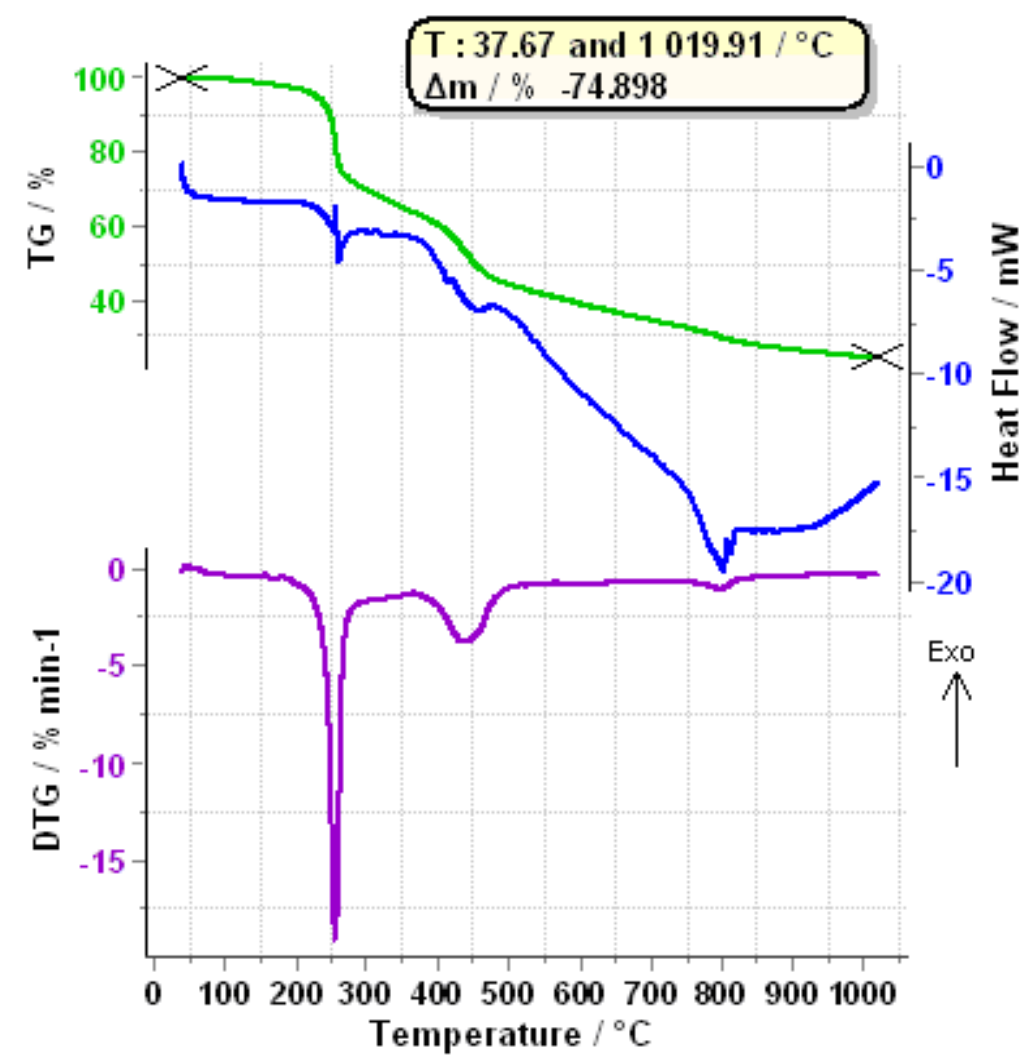

Fig. 11: TG-DTG-DSC trace of TTF $\left[\mathrm{Ni}(\mathrm{dmit})_{2}\right]_{2}$ molecule-based conductors grown in the presence of $[\mathrm{HDMIM}]\left[\left(\mathrm{CF}_{3} \mathrm{SO}_{2}\right)_{2} \mathrm{~N}\right](3$ molar eq. $)$ at $-50{ }^{\circ} \mathrm{C}$

From Fig. 11, step $1-61.4$ and $195.3{ }^{\circ} \mathrm{C}$, mass loss $3.8 \%$, step $2-198.2$ and $332.3{ }^{\circ} \mathrm{C}$, mass loss $32.4 \%$, step $3-$ 334.6 and $529.7^{\circ} \mathrm{C}$, mass loss $23.6 \%$, step $4-532.8$ and $730.1{ }^{\circ} \mathrm{C}$, mass loss $8.1 \%$ and step $5-732.7$ and $1,016.7{ }^{\circ} \mathrm{C}$, mass loss $8.9 \%$. The total mass loss is $77.4 \%$. It can be concluded, that the major part of the sample is lost in the second and third step (approx. 55\%).

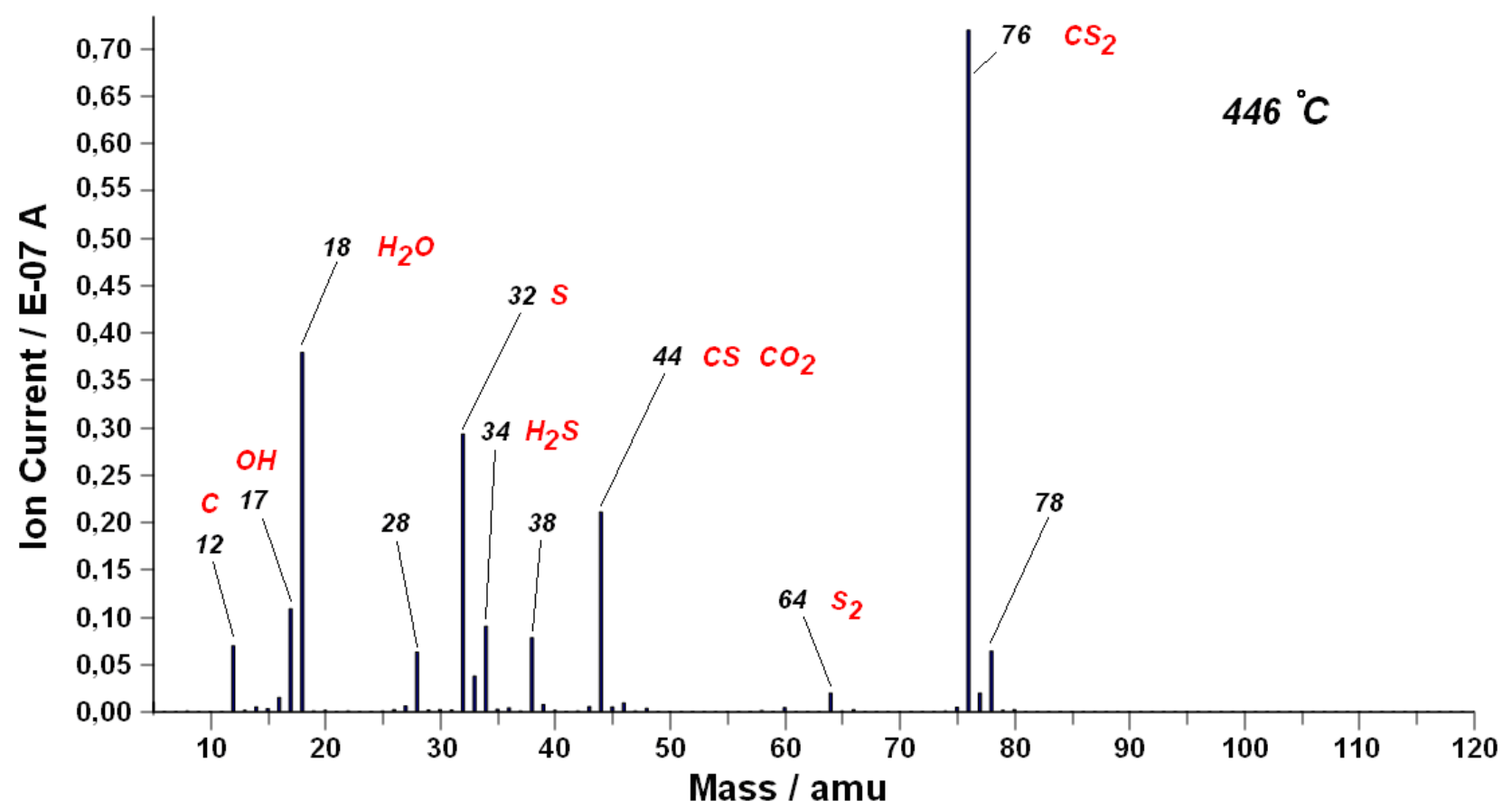


Fig. 12: Analog mass spectra of the evolved volatiles (at $\left.446^{\circ} \mathrm{C}\right)$ of $\operatorname{TTF}\left[\mathrm{Ni}(\mathrm{dmit})_{2}\right]_{2}$ molecule-based conductors grown in the presence of [HDMIM] $\left[\left(\mathrm{CF}_{3} \mathrm{SO}_{2}\right)_{2} \mathrm{~N}\right]$

(3 molar eq.) at $-50{ }^{\circ} \mathrm{C}$

By evaluating the mass spectrometric evolved gas analysis results of the gaseous products released at $446{ }^{\circ} \mathrm{C}$ (Fig. 12), one can see, that the major decomposition products are various sulfur compounds, such as carbonyl sulfide $\mathrm{CS}_{2}$ (m/z - 76 amu, parent ion and base peak), hydrogen sulfide $\mathrm{H}_{2} \mathrm{~S}(\mathrm{~m} / \mathrm{z}-34 \mathrm{amu})$ and diatomic sulfur molecule (m/z -64 $\mathrm{amu})$.

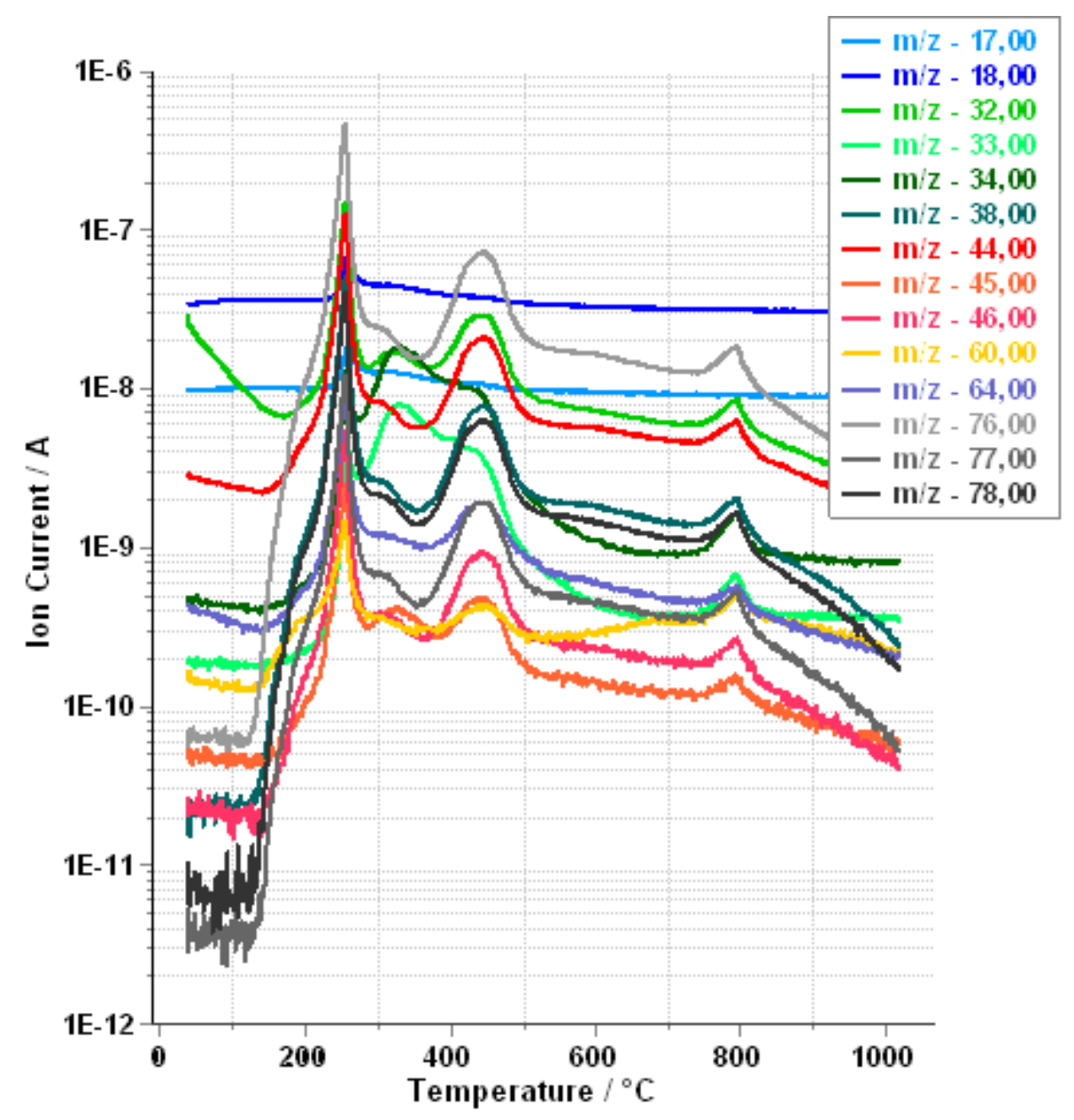

Fig. 13: Ion currents (concentration variation) of some selected fragments plotted against temperature

By following the course of the various fragments identified (Fig. 13), it can be stated, that the slow decomposition of the sample begins at quite low temperatures $\left(125^{\circ} \mathrm{C}\right)$, with evolution of $\mathrm{CS}_{2}(\mathrm{~m} / \mathrm{z}-76$ amu $)$, so the $\operatorname{TTF}\left[\mathrm{Ni}(\mathrm{dmit})_{2}\right]_{2}$ is less stable thermally. Between 290 and $390^{\circ} \mathrm{C}$ a strong evolution of $\mathrm{H}_{2} \mathrm{~S}(\mathrm{~m} / \mathrm{z}-34 \mathrm{amu})$ takes place.

\section{Conclusion}

In conclusion, we have prepared nanoparticles of the two well-known molecular conductors, TTF.TCNQ and $\mathrm{TTF}\left[\mathrm{Ni}(\mathrm{dmit})_{2}\right]_{2}$. Working in long-chain alkyl imidazolium salts/acetonitrile or acetone mixtures at low temperatures, particles of sizes in the 10-50 nm range were grown. However, the more interesting results in terms of state of dispersion and size control were obtained in the presence of the neutral amphiphilic molecule namely, $N$-octylfurfuryl- 
imine. Spherical nanoparticles as small as $5-15 \mathrm{~nm}$ were grown. This is remarkable for quasi-one dimensional systems whose natural tendency is to grow as elongated needles or wires. According to spectral, thermoanalytical, and conductivity data, nanoparticle powders had a similar behavior than those for bulk materials. We are currently investigating the use of other solvents and liquid surfactants (in various relative amounts) to grow and organize the conducting nanoparticles on conversion coatings for instance. In another hand, we consider the synthesis of composite materials by dispersing the nanoparticles in a polymer matrix. The resulting materials will undergo an integration in thermoelectric generators in order to assess their ability to convert heat energy into electrical energy.

\section{Acknowledgements}

The authors would like to thank CNRST-Morocco for a grant (S. F.) and Ministère de l'Enseignement Supérieur et de la Recherche-France for a grant (I. C.). We would also like to thank CNRS-Toulouse and Université Paul SabatierToulouse.

\section{References}

[1] Valade L, Tanaka H. Molecular Inorganic Conductors and Superconductors. In: Bruce DW, O'Hare D, Walton RI editors. Molecular Materials. John Wiley \& Sons, United Kingdom; 2010. pp. 211-280.

[2] Fraxedas J, Molecular Organic Materials - From Molecules to Crystalline Solids, Cambridge: Cambridge University Press; 2006.

[3] Cassoux P, Valade L, Molecular Inorganic Superconductors. In: Inorganic Materials. Second edition. Bruce DW, O’Hare D editors. John Wiley \& Sons, Chichester; 1996.

[4] Savy JP, de Caro D, Faulmann C, Valade L, Almeida M, Koike T, Fujiwara H, Sugimoto T, Fraxedas J, Ondarçuhu T, Pasquier C. Nanowires of molecule-based charge-transfer salts. New J. Chem. 2007;31:519-527.

[5] Lv J, Liu H, Li Y. Self-assembly and properties of low-dimensional nanomaterials based on $\pi$-conjugated organic molecules. Pure Appl. Chem. 2008;80:639-658.

[6] Ren L, Xian X, Yan K, Fu L, Liu Y, Chen S, Liu Z. A General Electrochemical Strategy for Synthesizing ChargeTransfer Complex Micro/Nanowires. Adv. Funct. Mater. 2010;20:1209-1223.

[7] Jung YJ, Kim Y, Kim GT, Kang W, Noh DY. Electrochemical Fabrication of (TMTSF $)_{2} \mathrm{X}\left(\mathrm{X}=\mathrm{PF}_{6}, \mathrm{BF}_{4}, \mathrm{ClO}_{4}\right)$ Nanowires. J. Nanosci. Nanotechnol. 2012;12:5397-5401.

[8] Bhatt A, Mechler Á, Martin LL, Bond AM. Synthesis of Ag and Au nanostructures in an ionic liquid: thermodynamic and kinetic effects underlying nanoparticle, cluster and nanowire formation. J. Mater. Chem. 2007;17:2241-2250.

[9] de Caro D, Jacob K, Faulmann C, Legros J.-P, Senocq F, Fraxedas J, Valade L. Ionic liquid-stabilized nanoparticles of charge transfer-based conductors. Synth. Met. 2010;160:1223-1227.

[10] de Caro D, Jacob K, Hahioui H, Faulmann C, Valade L, Kadoya T, Mori T, Fraxedas J, Viau L. Nanoparticles of organic conductors: synthesis and application as electrode material in organic field effect transistors. New J. Chem. 2011;35:1315-1319.

[11] de Caro D, Jacob K, Faulmann C, Valade L, Viau L. TTF[Ni(dmit $\left.)_{2}\right]_{2}$ : Now as nanoparticles. C. R. Chimie. 2012;15:950-954.

[12] de Caro D, Valade L, Faulmann C, Jacob K, Van Dorsselaer D, Chtioui I, Salmon L, Sabbar A, El Hajjaji S, Pérez

E, Franceschi S, Fraxedas J. Nanoparticles of molecule-based conductors. New J. Chem. 2013;37:3331-3336.

[13] Gonfa G, Bustam SA, Man Z, Adbul Mutalib MI. Unique Structure and Solute-Solvent Interaction in Imidazolium Based Ionic Liquids: A Review. Asian Transactions on Engineering. 2011;1(05):24-34. 
[14] Philippot K, Chaudret B. Organometallic Derived Metals, Colloids, and Nanoparticles. In: Crabtree RH, Mingos MP editors. Comprehensive Organometallic Chemistry III - From Fundamentals to Applications. Elsevier; 2007. pp. 71-99.

[15] de Caro D, Souque M, Faulmann C, Coppel Y, Valade L, Fraxedas J, Vendier O, Courtade F. Colloidal solutions of organic conductive nanoparticles. Langmuir. 2013;29(28):8983- 8988.

[16] de Caro D, Faulmann C, Valade L, Jacob K, Chtioui I, Foulal S, de Caro P, Bergez-Lacoste M, Fraxedas J, Ballesteros B, Brooks JS, Steven E, Winter LE. Four Molecular Superconductors Isolated as Nanoparticles. Eur. J. Inorg. Chem. 2014;24: 4010-4016.

[17] Wudl F. A new approach to the preparation of tetrathiafulvalenium salts. J. Amer. Chem. Soc. 1975;97(7):19621963.

[18] Steimecke G, Sieler HJ, Kirmse R, Hoyer E. First synthesis of complexes of $\mathrm{C}_{3} \mathrm{~S}_{5}{ }^{2-}$, Phosphorus Sulfur. 1979;7:4955.

[19] Bergez-Lacoste M, Thiebaud-Roux S, de Caro P, Fabre J.-F, Mouloungui Z. Dérivés du furfural pour une application biosolvants, Patent FR1351811, France; 2013.

[20] Sun Y, Sheng P, Di C, Jiao F, Xu W, Qiu D, Zhu D. Organic Thermoelectric Materials and Devices Based on $p$ and $n$-Type Poly(metal 1,1,2,2-ethenetetrathiolate)s. Adv. Mater. 2012;24:932-937.

[21] Chappell JS, Bloch AN, Bryden WA, Maxfield M, Poelher PO, Cowan DO. Degree of charge transfer in organic conductors by infrared absorption spectroscopy. J. Amer. Chem. Soc. 1981;103 (9):2442-2443.

[22] Kuzmany H, Stolz HJ. Raman scattering of TTF-TCNQ and related compounds. J. Phys. C: Solid State Phys. 1977;10:2241-2252.

[23] De Caro D, Fraxedas J, Faulmann C, Malfant I, Milon J, Lamère JF, Collière V, Valade L. Metallic thin films of $\mathrm{TTF}\left[\mathrm{Ni}(\mathrm{dmit})_{2}\right]_{2}$ by electrodeposition on (001)-oriented silicon substrates. Adv. Mater. 2004;16:835-838.

[24] Savy JP, De Caro D, Valade L, Legros JP, Auban-Senzier P, Pasquier CR, Fraxedas J, Senocq F. Superconductivity in TTF[Ni(dmit) $]_{2}$ films. EPL. 2007;78:37005/1-5.

[25] Liu G, Fang Q, Xu W, Chen H, Wang C. Vibration assignment of carbon-sulfur bond in 2-thione-1,3-dithiole-4,5dithiolate derivatives. Spectrochim. Acta A. 2004;60:541-550.

[26] Pokhodnya KI, Faulmann C, Malfant I, Andreu-Solano R, Cassoux P, Mlayah A, Smirnov D, Léotin J. Infrared and Raman properties of [M(dmit $\left.)_{2}\right](\mathrm{M}=\mathrm{Ni}, \mathrm{Pd})$ based compounds. Synth. Met. 1999;103:2016-2019.

[27] Bozio R, Zanon I, Girlando A, Pecile C. Vibrational spectroscopy of molecular constituents of one-dimensional organic conductors. Tetrathiofulvalene (TTF), $\mathrm{TTF}^{+}$, and $\left(\mathrm{TTF}^{+}\right)_{2}$ dimer. J. Chem. Phys. 1979;71:2282-2293.

[28] Siedle AR. Metal Complexes of Tetrathiafulvalene and Related Compounds. In: Miller JS editor. Extended Linear Chain Compounds. Volume 2. New York: Plenum Press; 1982. pp. 469-487.

[29] Muraoka Y, Imajo S, Yamashita S, Akutsu H, Nakazawa Y. Thermal anomaly around the superconductive transition of $\kappa-(\mathrm{BEDT}-\mathrm{TTF})_{2} \mathrm{Cu}(\mathrm{NCS})_{2}$ with external pressure and magnetic field control. J. Therm. Anal. Calorim. 2016;123:1891-1897.

[30] Ishikawa T, Yamashita S, Nakazawa Y, Kawamoto A, Oguni M. Calorimetric study of molecular superconductor $\kappa$-(BEDT-TTF $)_{2} \mathrm{Ag}(\mathrm{CN})_{2} \mathrm{H}_{2} \mathrm{O}$ which contains water in the anion layers. J. Therm. Anal. Calorim. 2008;92:435-438.

[31] Bhattacharjee A, Roy D, Roy M. Thermal degradation of a molecular magnetic material: $\{\mathrm{N}(n-$ $\left.\left.\mathrm{C}_{4} \mathrm{H}_{9}\right)_{4}\left[\mathrm{Fe}^{\mathrm{II}} \mathrm{Fe}^{\mathrm{III}}\left(\mathrm{C}_{2} \mathrm{O}_{4}\right)_{3}\right]\right\}_{\infty}$. J. Therm. Anal. Calorim. 2012;109:1423-1427. 